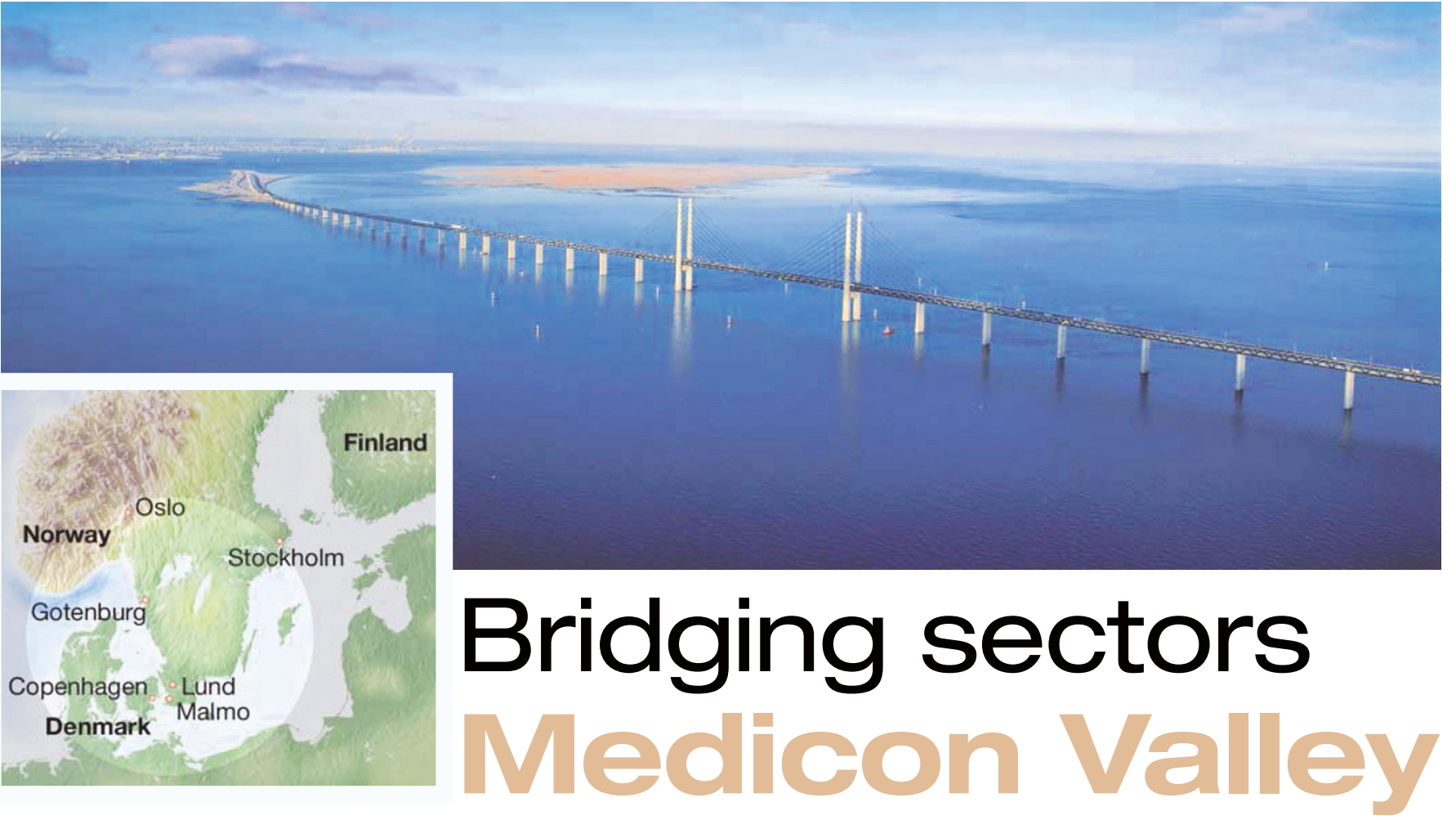

bridge spanning the Øresund Sound now connects biotech companies in southern Sweden and northern

Denmark. Associations with local universities tie the companies to the area, and a plethora of venture capital funds fuel them. But for Medicon Valley's growing body of biotech companies to take off, they need one more resource that is in increasingly short supply - scientists.

"The bottleneck used to be venture capital," says Anker Lundemose, chief executive of Pantheco, a Danish biotech company. "The bottleneck now is human resources." About 2,000 R\&D employees work in the region's 95 companies. But the growth in both new companies and venture funds means that more scientists will be needed.

The area must attract more talent from beyond what has traditionally been a fairly insular community, say area bankers, biotech executives and university administrators.
And it will also need to retain the best and brightest PhDs produced by the concentration of universities that created the Medicon Valley Academy the organization that basically organized the region's biotech into one operational unit (see Nature 395, 412-413; 1999).

Claus Bræstrup, executive vice-president, $R \& D$, of Lundbeck, the Copenhagenbased pharmaceutical firm, says companies will need to look outward more but successful overtures to researchers in other countries may not be easy. "There are major obstacles for people coming in to Denmark," Bræstrup says. "One is the taxes; another is the weather."

Denmark has already begun to address the tax system, which levies rates as high as $62 \%$ for the best-paid scientists. Last year, it established an 'expert' bracket, which allows out-of-country workers with skills in demand to pay only $25 \%$ for three years.

The country had a similar programme before, but it only applied to the highest-paid

\title{
Beyond the valley
}

In Odense, Denmark, biotechnology is becoming a way of life. In a recent inventory to seek out areas of economic growth, the local government identified 15 biotech companies and 22 medical technical firms, in addition to the area's academic institutions.

The government has since dubbed the region BioTEAM South and hopes that improved organization will help the area to build on earlier successes, such as the University of Southern Denmark's work relating to the recently sequenced genome of the malaria parasite

positions - and anyone deciding to stay on after three years was required to pay back the difference. More people are eligible under the new system, and the assimilation penalty no longer applies. But the tax break can cause resentment among co-workers who pay the higher rates, Bræstrup says.
Plasmodium falciparum.

Matthias Mann, a

bioinformatician at the university, worked with researchers from the Netherlands and the Sanger Institute near Cambridge, UK, to analyse the parasite's proteome.

Scientists in the region now hope to build on that success through the university's Centre for Proteome Analysis in Life Sciences. The area is also positioning itself for more international collaboration by joining the ScanBalt initiative (see page A3). BioTEAM South

www.bioteam.org

Lundbeck has recruited extensively outside the country — adding $117 \mathrm{R} \& \mathrm{D}$ workers in the past year and doubling its research budget in the past two. The company is especially short on organic chemists and bioinformatics experts.

Kirsten Drejer, chief executive of Symphogen, a 


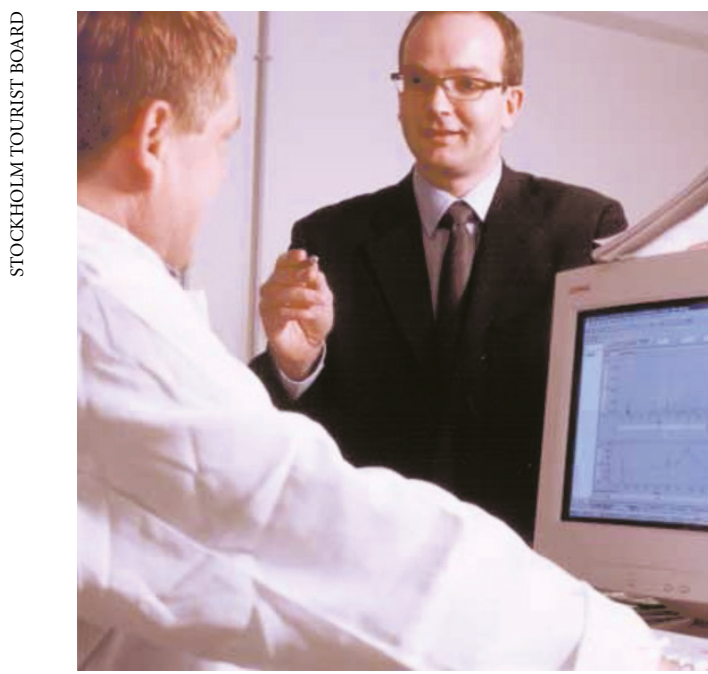

Pointing the finger: Pantheco chief executive Anker Lundemose pinpoints the shortage of scientists as the major bottleneck to biotech growth.

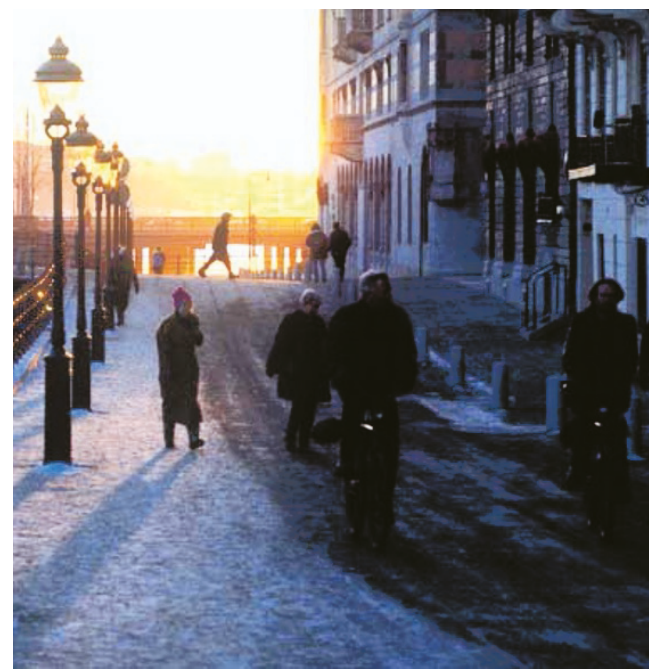

Cold comfort: the long, dark Scandinavian winter can act as a deterrent to scientists coming from warmer regions, according to some industry experts.
Danish biotech company specializing in developing human antibodies to viruses, says she is having an especially hard time finding senior people. She agrees with Bræstrup that the Scandinavian weather - especially the long, dark winter - can make it hard to recruit scientists from warm sunny regions such as California. "On the other hand, it's very safe," says Søren Mouritsen, chief executive of M\&E Biotech, one of the first Danish biotech companies. $\mathrm{He}$ tries to emphasize to recruits that the area is considered to offer excellent quality of life. successful in finding qualified candidates. It is important to offer a research setting in a non-academic environment, because academic slots have been increasingly scarce due to a dearth of government funding, Poulsen says.

Eva Degerman, from Lund University's section for molecular signalling, is concerned about a similar trend in Sweden, which is especially pronounced in Stockholm and Uppsala (see page A19). She would prefer not to have to rely on industry to fund her research. "I think it is important that we have our independence," she explains.
But that may become increasingly difficult. Degerman, like many Swedish scientists, depends on government and foundation money to support her work. These funds have not been rising nearly as fast as they have in the United States, and she is worried that too much dependence on industry money will result in less freedom to publish and an over-emphasis on product over basic research.

Per Belfrage, former dean of Lund's medical school, thinks that Medicon Valley-area academic scientists who learn to interact with the region's industry can help themselves retain their independence.

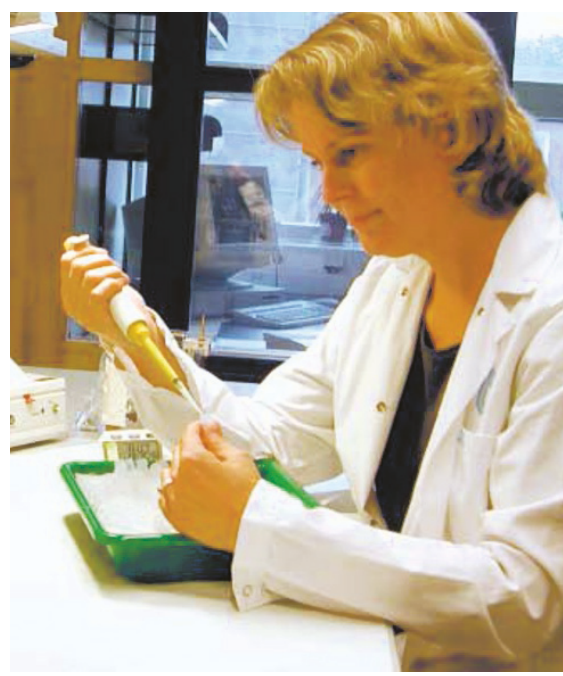

Independent streak: Lund University's Eva Degerman fears that reliance on industry funds will reduce academic freedom.

For example, if industrial and academic scientists band together under the aegis of the Medicon Valley Academy, they may be able to lobby successfully for more basic biomedical funding something scientists from both sectors say is lacking. Although the government cannot control the climate, it can do something about funding. Paul Smaglik is Naturejobs editor:

Medicon Valley Academy

www.mva.org

Copenhagen Capacity

www.copcap.com

whose company AROS Applied Biotechnology is designing diagnostic chips for cancer, is also a professor with the institute and employed by the hospital as a senior doctor.

Djurhuus welcomes such developments, but says that the downside is the possibility of less academic interaction. Danish science is "fragile" because of the relatively low level of public funding, Djurhuus says. Too much commercial work could disrupt the dialogue that exists between scientists receiving public and private funding, he adds. findings. As a result of this approach, he has been

The Institute of Experimental development, institutions Denmark's University of into a fashioning itself Sweden's Karolinska Institute, according to its director Jens doing this by emphasizing commercialization and industrial interaction, says Djurhuus, who is also president of the Danish Medical Research Council, a government advisory body.

But while the Karolinska Institute focuses much of its university-industry relations on drug discovery and at Aarhus are geared toward the out. For example, the two are now collaborating on ways to monitor in vivo physiology using a host of technologies.

As a result, about 20 members of the institute now have their own companies, and many split their time between their commercial interests, independent research and, in some cases, medicine. For example, Torben Ørntoft, 